\title{
Exploring the Connection Between Sleep and Cluster Headache: A Narrative Review
}

\author{
Joseph V. Pergolizzi Jr. · Peter Magnusson · Jo Ann LeQuang • \\ Charles Wollmuth · Robert Taylor Jr. · Frank Breve
}

Received: March 31, 2020 / Published online: May 7, 2020

(C) The Author(s) 2020

\section{ABSTRACT}

Cluster headache is a rare form of headache associated with sleep and even speculated to be a manifestation of a sleep disorder rather than a primary headache. Cluster headache exhibits both circadian and circannual rhythmicity. While attacks often occur during sleep, the implication that cluster headaches might be involved with rapid eye movement (REM) sleep phases has neither been fully established nor

Digital Features To view digital features for this article go to https://doi.org/10.6084/m9.figshare.12173517.

J. V. Pergolizzi Jr. · J. A. LeQuang ( $₫)$ · C. Wollmuth · R. Taylor Jr.

NEMA Research, Inc., Naples, FL, USA

e-mail: joannlequang@gmail.com

P. Magnusson

Cardiology Research Unit, Department of Medicine,

Karolinska Institutet, Stockholm, Sweden

P. Magnusson

Centre for Research and Development, Uppsala

University/Region Gävleborg, Gävle, Sweden

F. Breve

Department of Pharmacy Practice, School of

Pharmacy, Temple University, Philadelphia, PA, USA refuted. The regulatory mechanisms governing sleep including hypothalamic activity and the autonomic nervous system response may play a role. Hypothalamic activation has been observed in cluster headache patients during positron emission tomography testing, but only during attacks. While sleep apnea is associated with morning headaches in general, the link between sleep-disordered respiration and cluster headache remains elusive. Hypoarousal during sleep and periods of hypoxia are associated with cluster headache, the latter likely involving inflammatory processes rather than apnea. Further study is needed, as cluster headaches represent a serious primary cephalgia that is incompletely understood.

Keywords: Chronic cluster headache; Cluster headache; Cluster headache syndrome; Sleep 


\section{Key Summary Points}

The onset of cluster headache often occurs during sleep and cluster headaches have a diurnal and circannual rhythm.

Cluster headaches are characterized by agitation, wakefulness, and a desire to move around or pace, making somnography challenging.

The relationship between rapid eye movement (REM) sleep and cluster headache is controversial.

Insufficient, erratic, or disordered sleep may trigger cluster headaches in susceptible individuals.

People without cluster headache arouse 7-15 times an hour during healthy sleep but those with cluster headache arouse less often, possibly due to reduced hypothalamic activity.

The connection between sleep-disordered breathing and headache is well established, but it is not clear if cluster headaches are related to erratic breathing patterns during sleep.

Pain in cluster headache can be very severe and is the result of a cascade of event culminating in neurovascular inflammation involving the trigeminal nerve.

\section{INTRODUCTION}

The International Classification of Sleep Disorders recognizes specific types of sleep-related headache: cluster headache, hypnic headache, chronic paroxysmal hemicrania, and migraine [1]. The relationship between sleep and cluster headache (as well as other headaches) has been known for decades but the underlying neurological mechanisms have yet to be elucidated. It is particularly challenging to study sleep in cluster headache patients, since prevalence is about $0.1 \%$ [2] and attacks are often characterized by wakefulness, agitation, and a desire to pace, making conventional somnographic evaluations very challenging. The paroxysmal onset of a cluster headache often occurs during sleep [3], and, unlike other forms of sleep-related headaches, cluster headaches exhibit a very pronounced diurnal relationship in addition to a circannual rhythmicitiy [4]. It has been speculated that cluster headache patients may have worse sleep quality than controls or even that cluster headache is the manifestation of a sleep disorder [5]. Unlike migraine headaches, sleep does not relieve cluster headache [6]. In fact, cluster headache patients typically exhibit agitation during an attack.

The etiology of cluster headache is unknown. More men than women suffer from cluster headaches in a 4:1 ratio [2]. Episodic attacks are more common, which generally occur for a period of about two months and then remit, sometimes for years. Chronic cluster headache has no such periods of remission although attacks wax and wane with the seasons [7]. The lifetime prevalence of cluster headache is $0.4 \%$ [8].

People who have difficulty sleeping have a greater probability of having headaches of all kinds over 3 months compared to those without sleep difficulties (75 vs. $24 \%$, odds ratio 4.8) [9]. Furthermore, people with headache are more likely than others to report symptoms often associated with poor sleep: daytime sleepiness, fatigue, and insomnia $[10,11]$. What is not clear is whether sleep disorders cause headache or vice versa, or if some more complex mechanisms are involved [12].

The aim of this narrative review is to examine the literature on cluster headache with respect to sleep to present what is currently known, unknown, and where our knowledge gaps remain. While much can be learned about cluster headache from a large body of knowledge and research on the more ubiquitous migraine headache, cluster headaches are a unique and rare form of primary cephalgia. 


\section{METHODS}

In January and February 2020, the authors searched PubMed for keywords "sleep headache," "sleep-disordered headache," which yielded 4094 and 82 results, respectively. Many of these articles involved headache types other than cluster headache. The keywords "sleep cluster headache" found 191 results and "cluster headache" 4122 results. The authors selected the articles most appropriate to the topic of the relationship of sleep specific to cluster headache. In some cases, the bibliographies of key articles were also searched for supplemental material. This is a narrative review intended to summarize the current state of understanding of the subject of cluster headache and its relationship to sleep.

This article is based on previously conducted studies and does not contain any studies with human participants or animals performed by any of the authors.

\section{Pain in Cluster Headache}

Cluster headache is characterized by a paroxysmal onset of severe unilateral typically periorbital pain that often peaks in intensity in a matter of moments; pain can be so severe that the disorder has been nicknamed the "suicide headache" [13, 14]. Attacks are described as bouts, each lasting about $15 \mathrm{~min}$ to $3 \mathrm{~h}$, then resolving spontaneously, only to repeat the cycle again over a period of hours or days, i.e., "clusters". Cluster headaches are associated with rhinorrhea, lacrimation, drooping eyelids, and nasal congestion [14] (see Fig. 1).

Cluster headaches have three pathophysiological phases. In the first phase, chronobiological aberrations emerge that impair the body's sympathetic nervous system, interfere with chemoreceptor activity, and make the individual vulnerable to attack [7]. In the second phase, cluster induction is promoted and sustained by the persistent dysfunction of the chemoreceptors accompanied by sustained periods of hypoxia, whether induced by sleep apnea, vasodilation, or other causes. The third and final phase of cluster headache involves the

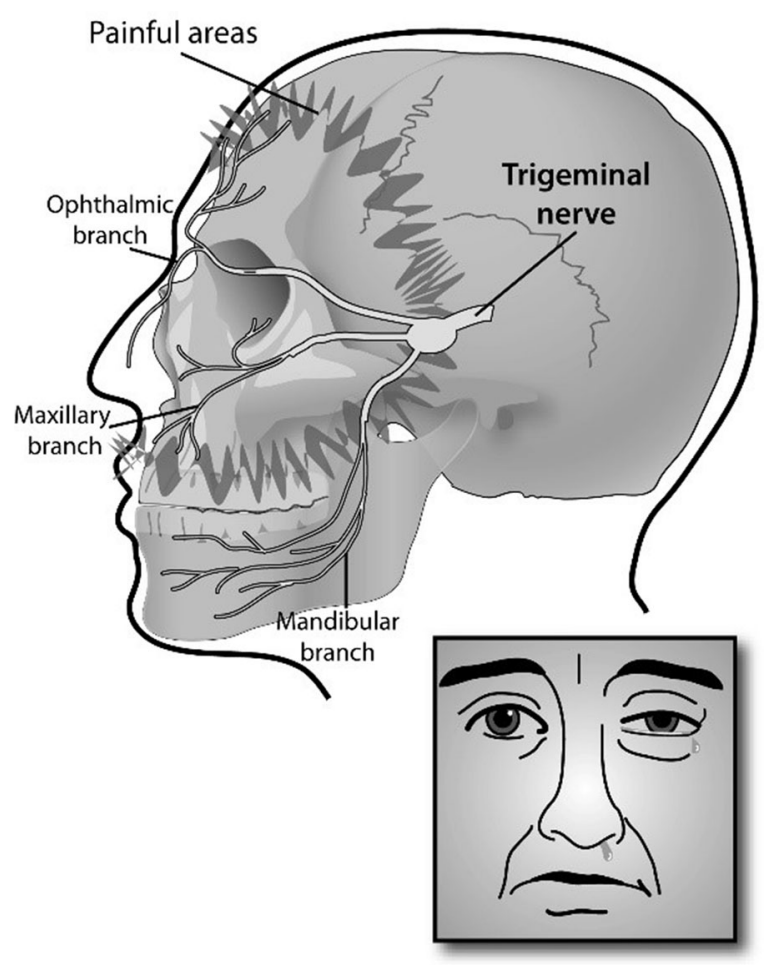

Fig. 1 The unilateral pain of cluster headache is associated with trigeminal nerve involvement and can result in severe pain, typically around one eye. Art courtesy of Todd Cooper of Coyote Studios, Green Valley, California

actual signs and symptoms of an attack, culminating in trigeminal nerve stimulation and a parasympathetic response [7].

Cluster headache pain is associated with activation of the trigeminal nerve that, in turn, leads to a vascular response in the form of pronounced vasodilatation. Based on the trigeminovascular paradigm of cluster headache attack, the headache is the result of a cascade of events culminating in neurovascular inflammation involving primarily the trigeminal nerve [7]. Recent advances in our understanding of the calcitonin gene-related peptide (CGRP) and the adenylate cyclase-activating peptide associated with the pituitary gland are known to not only dilate the vascular system but also modulate nociceptive neuronal pathways within the trigeminal system [15]. Thus, current understanding is that a neurological process commences the cascade, which triggers the vasodilatation leading to the painful cluster 
headache attack [15]. The neurovascular effects of cluster headache, known as coupling, suggest that cluster headache is first and foremost a neurological condition, with vasodilatation being the result rather than the cause of trigeminal activation [15].

\section{Rapid Eye Movement (REM) Sleep and Cluster Headache}

While there are a number of known triggers for cluster headache, including histamines, alcohol, nitroglycerine, meteorological or atmospheric changes, and stress, it is not clear if sleep can properly be called a trigger [7]. In a study of episodic and chronic cluster headache patients, $80 \%$ said that nocturnal sleep could trigger a headache, but only one-third said that napping could trigger a headache [16, 17]. If cluster headaches are primarily neurological disorders, then the underlying neurological mechanisms associated with sleep may play a role. Cluster headaches often but not always occur during sleep [18] and since they often start about 90 min into the sleep cycle, it had been speculated that they may be synchronized to specific phases of sleep, in particular rapid eye movement (REM) sleep or the transition into and out of REM sleep phases [17]. REM sleep was first described in medical literature when investigators could correlate specific brain-wave activity on the electroencephalogram with periods of rapid eye movements; it is during REM sleep that dreams occur $[19,20]$. The role of REM sleep remains to be more fully elucidated but likely includes enhancements to learning ability, consolidation of memories, and regulation of neuronal synapses [21]. REM sleep appears to be regulated by the body's natural circadian rhythms [21].

However, the connection between REM sleep and cluster headache remains controversial. A few anecdotal reports in the literature describe that a few patients who suffered a cluster headache could recall their dreams vividly around the time of the attack, suggesting the attack began in REM sleep [6]. However, unlike migraineurs who have marked distinguishing aspects to their dream, no such oneiric distinctions have yet been discovered in the dreams of cluster headache patients [22-26]. A few small studies have shown that episodic but not chronic cluster headache patients did indeed suffer attacks during REM sleep, other studies were equivocal or found no evidence of such a relationship [27-29].

REM density is the frequency of rapid eye movements during REM sleep and may be used a clinical metric; it has been proposed that low REM density may be a marker for sleep deprivation [30]. In a study of 40 cluster headache patients and 25 matched controls, cluster headache patients had significantly lower REM density (17.3 vs. $23.0 \%, p=0.0037)$ and significantly longer sleep latency $(2.0$ vs. $1.2 \mathrm{~h}$, $p=0.0012)$ although there were no differences in the groups for sleep apnea [17]. REM density has been studied in the first REM phase of sleep as a potential marker for liability to mood disorders [31]. Increased REM density has been associated with depressive symptoms and, indeed, variations in normal REM patterns are considered overall possible biomarkers for depression [32]. Thus, the relationship between REM sleep aberrations and cluster headache remain to be elucidated.

\section{Circadian and Circannual Rhythms}

The intriguing aspect in cluster headaches, which sets them apart from many other headache disorders, is that they exhibit a very pronounced circadian as well as a circannual rhythmicity [14]. Cluster headaches often commence in early night $[4,14,33]$ and bouts display a marked periodicity with greater incidence around both summer and winter solstice [34]. It has been speculated that the natural light/dark cycles are most pronounced as these time periods which might place undue stress on vulnerable homeostatic systems [18]. Cluster headache attacks are more common at night than during the day and often recur at specific clock times [35]. Attacks tend to decrease toward the end of spring and remain low over the summer and into early autumn when they ramp up again [4]. 
The "free-running" circadian cycle in healthy humans is on average $24.1 \mathrm{~h}$ and a healthy individual relies on external cues of light and dark to entrain the body's internal circadian cycle to accommodate the astronomical day [36]. The suprachiasmatic nucleus in the hypothalamus helps regulate the internal circadian clock using specific regions in the brain and the autonomic nervous system [37]; the suprachiasmatic nucleus may help time the release of hormones such as melatonin from the pineal gland $[37,38]$. The circadian nature of cluster headaches has caused some investigators to speculate that cluster headaches may be manifestations of a sleep disorder [5]. It is currently thought that the master clock function of the suprachiasmatic nucleus in the brain is responsible for the body's internal circadian rhythms. However, the suprachiasmatic nucleus has many other functions, including regulating entry into REM sleep. Thus, dysfunctions in the suprachiasmatic nucleus may disrupt sleep architecture, impair transitions into REM sleep, and result in longer-than-needed sleep times [39]. The disrupted REM sleep sometimes evident in cluster headache patients may be caused by hypothalamic changes affecting REM sleep rather than entering and exiting REM phases precipitating hypothalamic changes [17].

It has been suggested that the body's internal clock in the hypothalamus may be involved in cluster headache and a polymorphism of the PER3 gene associated with the hypothalamic clock was investigated in a study of healthy patients versus cluster headache patients and found no associated between PER3 variable number tandem repeat polymorphisms and cluster headache [40].

\section{Cluster Headache and the Brain}

The regulatory mechanisms of sleep are not thoroughly understood, but include circadian rhythmicity, autonomic nervous system responses, and hypothalamic activity [41, 42]. The hypothalamus regulates the body's natural circadian rhythms and controls sleep cycles [43]. Rapid eye movement (REM) sleep is controlled by cells in the brain described as REM-on and REM-off cells [44]. It is known that the ventrolateral periaqueductal gray (vPAG) area of the brain activated REM-off sleep and is does so in response to orexinergic inputs coming from the lateral hypothalamus [44]. Thus, when the ventrolateral periaqueductal gray region of the brain is stimulated by orexin, it inhibits nociception in the trigeminal nucleus caudalis. Erratic or irregular sleep can disrupt or interrupt hypothalamic inputs to the ventrolateral periaqueductal gray areas of the brain, which might explain how disordered sleep triggers headaches $[43,44]$ (see Fig. 2).

Hypothalamic activation has been observed in cluster headache patients during positron emission tomography testing, but only during attacks $[45,46]$. Studies of cluster headache patients using nuclear magnetic resonance imaging (MRI) demonstrated a degree of hypothalamic asymmetry [47]. A task-free study

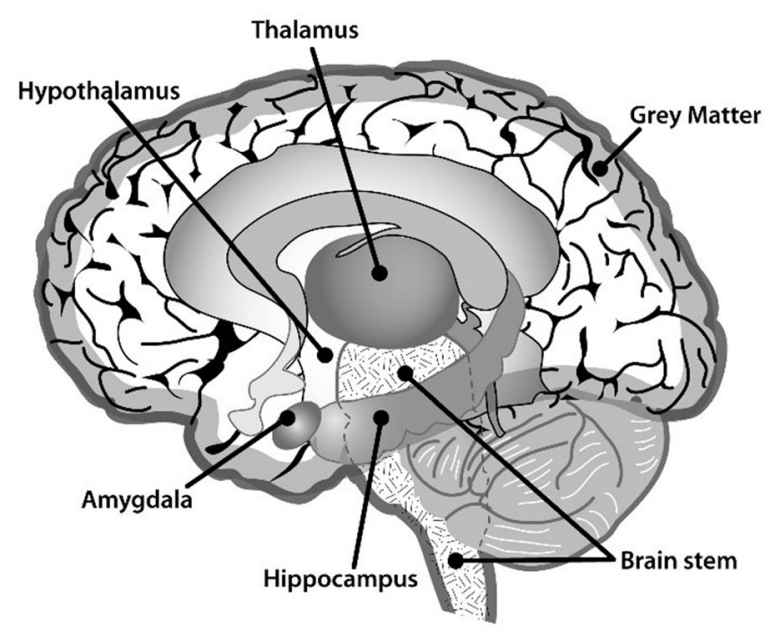

Fig. 2 The hypothalamus constitutes less than $1 \%$ of the brain by volume, but it is involved in numerous important processes, including regulation of the limbic system and regulation of the body's autonomic nervous system. It regulates arousal during sleep, the synthesis of many hormones, and the body's circadian clock. The nuclei in the brain stem and spinal autonomic ganglia receive afferent inputs from the periphery, which are delivered via the spinal cord and brainstem to the hypothalamus. The autonomic nervous system regulates the trigeminal nerves of the face which may play a role in headache pain as well as rhinorrhea, lacrimation, and nasal congestion associated with cluster headache. Art courtesy of Todd Cooper of Coyote Studios, Green Valley, California 
using positive emission tomography scanning in 21 cluster headache patients suggests that the posterior hypothalamus may be hyperexcitable in people with cluster headaches outside of bouts and that this excitability to external painful stimuli diminishes during the bout, possibly because of hyperactivity and neurotransmitter exhaustion due to too-frequent activation [48]. Cluster headache patients also appear to have a larger-volume postero-inferior hypothalamus than patients without cluster headaches [47]. Since the hypothalamus participates in the body's response to light by regulating the pituitary adenylate cyclaseactivating peptide (PACAP) [18], a role for PACAP in cluster headache has been implicated. PACAP is a signaling molecule that plays a role in both parasympathetic and hypothalamic systems, but it has not been studied in terms of its relationship to sleep [18]. In susceptible individuals, PACAP can trigger a migraine headache, but it is not clear if it might induce a cluster headache $[49,50]$. In fact, despite different symptomatologies, there may be considerable overlap in the mechanisms of these neurovascular headaches. Neuroimaging studies have provided evidence that abnormal hypothalamic activation occurs in various headache disorders, including but not limited to cluster headache $[45,49,51-54]$.

PACAP is distributed in both peripheral and central nervous systems [55]. It is known to exist in two forms, PACAP-27 and PACAP-38 [18]. PACAP is related to vasoactive intestinal peptide (VIP) and peptide histidine methionine [18]. Both PACAP and VIP have an affinity for the body's VPAC-1 and VPAC-2 receptors, but PACAP alone has an affinity for the PAC-1 receptor [56]. Animal studies have provided evidence that while PACAP can induce trigeminal neuralgia, VIP does not. This suggests that PAC-1 antagonism may be the better drug development target for neurovascular headache than VIP receptors [57]. While concentrations of PACAP-38 are heightened during migraine headache, in cluster headaches, PACP-38 increases only during the bout (phase three) but declines during interictal phases of an attack [58].
PACAP injection can induce migraine, but such tests have not been undertaken specifically in cluster headache [59]. From animal studies, it is known that both types of PACAP cross the blood-brain barrier with PACAP-38 being saturable and PACAP-27 non-saturable [60, 61]. The pineal gland is located outside of the blood-brain barrier but has fibers that react to PACAP; in animal studies, the pineal gland seems to exhibit signs of circadian rhythm, but PACAP levels do not have circadian variations [62]. Since PACAP can stimulate the production of endogenous melatonin, and since this occurs outside of the boundaries of the blood-brain barrier, it is at least plausible that intravenous PACAP could modulate sleep-wake cycles. However, data from human subjects and animals have produced conflicting results $[63,64]$ and suggests that PACAP synthesis and effects are complex [18]. Indeed, PACAP has not been thoroughly studied in humans [65].

Brain scans have confirmed that there is hypothalamic activation during cluster headache bouts and cluster headache patients have more hypothalamic grey matter volume than controls $[45,46]$. The idea of hypothalamic involvement is supported by the fact that there are often endocrinological changes in patients during cluster headache attacks, the attacks have rhythmicity, and deep brain stimulation of the posterior hypothalamus can improve refractory cluster headache $[16,66,67]$.

Produced in the hypothalamus, hypocretin (HCRT) is a neuropeptide, sometimes differentiated as orexin A (HCRT-1) and orexin B (HCRT-2) [68]. (HCRTs play a crucial role in regulating sleep cycles, arousal from sleep, and homeostatic maintenance and may even be involved in pain processing [68]. HCRT-1 and -2 both bind with equal affinity to HCRT-1 receptors, but HCRT-2 has a vastly greater affinity for the HCRT-2 receptor than HRCT-1 [69]. The importance of HCRTs in sleep is demonstrated by the fact that people with narcolepsy have very low and sometimes even undetectable levels of HCRT in their cerebrospinal fluid [70]. From a study of 26 cluster headache patients matched to 27 controls, cluster headache patients had significantly lower levels of 
HCRT-1 (382 vs. $431 \mathrm{pg} / \mathrm{ml}, p=0.004)$ than people without cluster headache [16].

Melatonin is normally secreted by the pineal gland based on input from the suprachiasmatic nucleus of the hypothalamus which, in turn, responds to changing levels of environmental light. Cluster headache patients have impaired melatonin production with less melatonin produced particularly during bouts [71]. In a healthy individual, melatonin temporarily enhances the inhibitory effects of gamma aminobutyric acid (GABA) which reduces the pain threshold and blunts anxiolysis. Melatonin regulates the influx of calcium into cells and, in such a way, can change vasoreactivity of cerebral vasculature by modulating serotonin (5HT2) receptors in these blood vessels. Serotonin antagonists such as flunarizine, methysergide, and cyproheptadine, have been found effective in treatment of cluster headache [6]. Melatonin may also be effective in treating cluster headache in that it inhibits prostaglandin synthesis, which plays a crucial role in vascular inflammation; prostaglandin E2 activates the nociceptive afferents of the trigeminovascular system [72].

\section{Arousal During Sleep and Cluster Headache}

During healthy sleep, an individual arouses briefly 7-15 times per hour. Arousal during sleep may be an adaptive function aimed at keeping the sleeper aware of potential dangers around him, but it is unclear if they serve any other function [73]. Cluster headache patients have been shown to arouse less often in sleepand this hypoarousal has implicated reduced activity from the hypothalamus and brainstem upward toward the cortex [17].

Advances in somnography have revealed the presence of micro-arousals during sleep, defined as paroxysmal shifts in EEG frequency that last $<3 \mathrm{~s}$. These arousal phases-during which the subject wakens but sleep resumes quicklyare normal in humans and their occurrence seems to increase with age. It is suspected that these brief arousals are triggered by the basal forebrain, the thalamus, the hypothalamus, and/or the brainstem likely working together in ascending pathways. Patients with migraine and cluster headache have fewer such arousals than people without such headaches, suggesting that a dysfunction in this system may play into headache onset $[16,17,74,75]$. A healthy adult experiences 7-15 arousals per hour during sleep that allow the sleeper to change position, cough, or check exposure to cold. This alternating sequence of active sleep and quiet sleep is described as the cyclic alternating pattern (CAP) [76].

\section{Sleep-Disordered Breathing and Cluster Headache}

Sleep-disordered breathing has been implicated in many types of headache, including obstructive sleep apnea. Since hypoxia has been observed in cluster headache patients, the role of sleep apnea has been studied with respect to the etiology of cluster headache. Obstructive sleep apnea occurs when the upper airways are partially or completely blocked during sleep, resulting in disordered breathing that includes typically hypopnea and/or apnea, oxygen desaturation, and disrupted sleep that is not always severe enough to awaken the subject completely [77]. Headaches, including but not limited to cluster headaches, can be associated with sleep apnea, but so-called "sleep apnea headache" does not have specific symptomology that sets it apart from other forms of headache, although headache is more common in people with sleep apnea than the general population [77]. Sleep-apnea headache is often chronic, occurring $>15$ days a month. A crosssectional study of patients with sleep apnea syndrome found $18 \%$ "often" or "very often" had a headache when they first got up compared to about $5 \%$ of the general population [78]. Sleep-apnea headaches are homeostatic disturbances and, like cluster headaches, are present upon arising and are relieved when the apnea is effectively treated [1]. Sleep-apnea headaches are frequent (usually at least 15 days per month) and do not occur with photophobia, phonophobia, or nausea [1]. Among people with clinically diagnosed obstructive sleep 
apnea, the prevalence of headache ranges from 32.9 to $58.5 \%$, but the most frequently reported manifestation is the tension-type headache [79]. However, the rate of obstructive sleep apnea is not higher in patients attending specialty headache clinics than the general population [80].

\section{Other Factors in Cluster Headaches}

Cluster headache attacks are known to occur simultaneously with increases in heart rate and blood pressure [3]. The time-frequency decomposition (TFD) of instantaneous heart rate variability (HRV) is an accepted measure for autonomic nervous system function. In a study of 20 subjects (seven with cluster headache during a period of active attacks, six controls, and seven with cluster headache during a quiet period), Holter monitoring data were obtained to examine RR intervals throughout the monitoring period (awake and asleep periods) as well as during sleep. All cluster patients (active and quiet) had a six-fold increased risk for suspected obstructive sleep apnea compared to control patients and changes in autonomic function measured by HRV were detected only in cluster headache patients during active periods; during quiet periods, the cluster headache patients in this study had normal autonomic function [3].

In a study of cluster headache patients, the prodromal phase was studied in 80 patients with episodic and chronic cluster headache. In $83.3 \%$ of patients, prodromal symptoms occurred, warning the patient of an impending attack [81]. Although cluster headaches do not have aura as do some migraine headaches, prodromal warning symptoms for cluster headache appear worthy of greater study.

Lifestyle factors may also play a role in cluster headache. In a study of 600 patients between the ages of 18 and 65 years, cluster headache patients were more likely than controls to have an unhealthy lifestyle $(48.3$ vs. $9.0 \%$, $p<0.001)$, to be a current or former smoker (74.5 vs. $30.0 \%, p<0.001$ ), to be more overweight (mean BMI was 26.1 vs. $24.2, p<0.001$ ), and to drink more alcohol each week (98.2 vs. $77.9 \mathrm{~g}, p=0.033)$ [42]. However, alcohol consumption in cluster headache patients is often stopped or drastically reduced during symptomatic spells [82]. In fact, some studies have suggested that people with cluster headache overall drink less alcohol than control patients [83]. Other lifestyle factors may be beyond the patient's control, for instance, parental cigarette smoking is markedly higher among cluster headache patients than controls [84]. None of these factors relate to sleep but suggest that the etiology of cluster headache may include, but not be limited to, sleep rhythms.

\section{DISCUSSION}

Cluster headaches share few things in common with the more common migraine headache, with which they are sometimes confused. Migraines are more prevalent (about $12 \%$ of general population compared to $<1 \%$ affected by cluster headache), affect women more than men (opposite of cluster headache), and likely involve genetic factors that are less clear with cluster headache. Aura, photophobia, phonophobia, and nausea do not occur with cluster headache, just as lacrimination, rhinorrhea, and seasonal attack patterns do not occur with migraines. Nevertheless, both are neurovascular headaches and are associated with intense pain, reduced quality of life, and even disability [85].

The relationship between sleep and cluster headache has been known for decades but has not yet been fully elucidated. Since attacks often occur during sleep and are not relieved by sleep, it has been tempting to view sleep as a trigger for cluster headache, but the circadian and circannual rhythmicity of attacks deserves special focus. Variations in the circadian rhythm have been associated with migraine as well, although the associations are less pronounced than with cluster headache [86]. Cluster headaches may involve an intricately synchronized interplay among hypothalamic activity, inflammation of the trigeminal system, and the autonomic nervous system [87].

Most people with cluster headaches do not get adequate treatment [88]. Misdiagnosis is more likely to occur in women than men 
because cluster headaches more typically afflict men and migraines women [83]. When women have cluster headaches, onset may be earlier $[89,90]$, and studies suggest that women with cluster headaches are more prone to develop chronic cluster headaches than men [91]. In a survey $(n=20)$, cluster headache patients report that they feel most physicians are not very knowledgeable about cluster headache and that people around them, including family and friends, do not understand their illness [92]. Half of the cluster headache patients surveyed said they would not tell an employer about their headaches for fear of losing their job [92].

\section{CONCLUSIONS}

New research into hypothalamic activity suggests that cluster headaches may be more of a disorder of the brain than a sleep disorder, as was once speculated. More research is required to better understand the etiology and pathogenesis of this severe form of headache.

\section{ACKNOWLEDGEMENTS}

Funding. No funding or sponsorship was received for this study or publication of this article.

Authorship. All named authors meet the International Committee of Medical Journal Editors (ICMJE) criteria for authorship for this article, take responsibility for the integrity of the work as a whole, and have given their approval for this version to be published.

Disclosures. Peter Magnusson, Jo Ann LeQuang, Charles Wollmuth, Robert Taylor, Jr. and Frank Breve have nothing to disclose. Joseph V. Pergolizzi, Jr. is a member of the journal's Editorial Board.

Compliance with Ethics Guidelines. This article is based on previously conducted studies and does not contain any studies with human participants or animals performed by any of the authors.

Data Availability. Data sharing is not applicable to this article, as no datasets were generated or analyzed during the current study.

Open Access. This article is licensed under a Creative Commons Attribution-NonCommercial 4.0 International License, which permits any non-commercial use, sharing, adaptation, distribution and reproduction in any medium or format, as long as you give appropriate credit to the original author(s) and the source, provide a link to the Creative Commons licence, and indicate if changes were made. The images or other third party material in this article are included in the article's Creative Commons licence, unless indicated otherwise in a credit line to the material. If material is not included in the article's Creative Commons licence and your intended use is not permitted by statutory regulation or exceeds the permitted use, you will need to obtain permission directly from the copyright holder. To view a copy of this licence, visit http://creativecommons.org/licenses/by$\mathrm{nc} / 4.0 /$.

\section{REFERENCES}

1. Olesen J. The international classification of headache disorders, 2nd edition: application to practice. Funct Neurol. 2005;20:61-8.

2. Fischera M, Marziniak M, Gralow I. The incidence and prevalence of cluster headache: a meta-analysis of population-based studies. Cephalgia. 2008;28: 614-8.

3. Baharav A, Shinar Z, Akselrod S, Mosek A, Davrath LR. Cluster headache patients have normal circadian and sleep time autonomic nervous system function. IEEE. 2005;2005:263-6.

4. Barloese M, Lund N, Petersen A, Rasmussen M, Jennum P, Jensen R. Sleep and chronobiology in cluster headache. Cephalalgia. 2015;35(11):969-78.

5. Holland PR, Goadsby PJ. Cluster headache, hypothalamus, and orexin. Curr Pain Headache Rep. 2009;13(2):147-54. 
6. Barloese M, Jennum P, Knudsen S, Jensen R. Cluster headache and sleep, is there a connection? A review. Thousand Oaks: SAGE Publications; 2012.

7. Kudrow L. The pathogenesis of cluster headache. Curr Opin Neurol. 1994;7(3):278-82.

8. Hagen K, Åsberg AN, Uhlig BL, et al. The epidemiology of headache disorders: a face-to-face interview of participants in HUNT4. J Headache Pain. 2018;19(1):25.

9. Boardman HF, Thomas E, Millson DS, Croft PR. Psychological, sleep, lifestyle, and comorbid associations with headache. Headache J Head Face Pain. 2005;45(6):657-69.

10. Jennum P, Jensen R. Sleep and headache. Sleep Med Rev. 2002;6(6):471-9.

11. Paiva T, Batista A, Martins P, Martins A. The relationship between headaches and sleep disturbances. Headache J Head Face Pain. 1995;35(10): 590-6.

12. Paiva T. Sleep and headache. Handb Clin Neurol. 2011;99:1073-86.

13. Ji Lee M, Cho SJ, Wook Park J, et al. Increased suicidality in patients with cluster headache. Cephalalgia. 2019;2019:333102419845660.

14. Rozen TD, Fishman RS. Cluster headache in the United States of America: demographics, clinical characteristics, triggers, suicidality, and personal burden. Headache. 2012;52(1):99-113.

15. Hoffmann J, Baca SM, Akerman S. Neurovascular mechanisms of migraine and cluster headache. J Cereb Blood Flow Metab. 2019;39(4):573-94.

16. Barloese MCJ. Neurobiology and sleep disorders in cluster headache. J Headache Pain. 2015;1:1.

17. Barloese MC, Jennum PJ, Lund NT, Jensen RH. Sleep in cluster headache-beyond a temporal rapid eye movement relationship? Eur J Neurol. 2015;22(4): 656-e640.

18. Holland PR, Barloese M, Fahrenkrug J. PACAP in hypothalamic regulation of sleep and circadian rhythm: importance for headache. J Headache Pain. 2018;19(1):20.

19. Aserinsky E, Kleitman N. Regularly occurring periods of eye motility, and concomitant phenomena, during sleep. Science. 1953;118(3062):273-4.

20. Dement W, Kleitman N. The relation of eye movements during sleep to dream activity: an objective method for the study of dreaming. J Exp Psychol. 1957;53(5):339-46.
21. Peever J, Fuller PM. The biology of REM sleep. Curr Biol. 2017;27(22):R1237-r12481248.

22. De Angeli F, Lovati C, Giani L, et al. Negative emotions in migraineurs dreams: the increased prevalence of oneiric fear and anguish, unrelated to mood disorders. Behav Neurol. 2014;2014:919627.

23. Heather-Greener GQ, Comstock D, Joyce R. An investigation of the manifest dream content associated with migraine headaches: a study of the dreams that precede nocturnal migraines. Psychother Psychosom. 1996;65(4):216-21.

24. Levitan H. Dreams which culminate in migraine headaches. Psychoter Psychosom. 1984;41(4): 161-6.

25. Lippman C. Recurrent dreams in migraine: an aid to diagnosis. J Nerv Ment Dis. 1954;120(3-4):273-6.

26. Lovati C, DeAngeli F, D'Amico D, et al. Is the brain of migraineurs "different" even in dreams? Neurol Sci. 2014;35(Suppl 1):167-9.

27. Dexter JD, Weitzman ED. The relationship of nocturnal headaches to sleep stage patterns. Neurology. 1970;20(5):513-8.

28. Kudrow L, McGinty D, Phillips E. Sleep apnea in cluster headache. Cephalalgia. 1984;4:33-8.

29. Zaremba S, Holle D, Wessendorf TE, Diener HC, Katsarava Z, Obermann M. Cluster headache shows no association with rapid eye movement sleep. Cephalalgia. 2012;32(4):289-96.

30. Lucidi F, Devoto A, Violani C, De Gennaro L, Mastracci P, Bertini M. Rapid eye movements density as a measure of sleep need: REM density decreases linearly with the reduction of prior sleep duration. Electroencephalogr Clin Neurophysiol. 1996;99(6): 556-61.

31. Battaglia M, Ferini Strambi L, Bertella S, Bajo S, Bellodi L. First-cycle REM density in never-depressed subjects with borderline personality disorder. Biol Psychiatry. 1999;45(8):1056-8.

32. Wang YQ, Li R, Zhang MQ, Zhang Z, Qu WM, Huang ZL. The neurobiological mechanisms and treatments of REM sleep disturbances in depression. Curr Neuropharmacol. 2015;13(4):543-53.

33. Ofte HK, Berg DH, Bekkelund SI, Alstadhaug KB. Insomnia and periodicity of headache in an arctic cluster headache population. Headache. 2013;53(10):1602-12.

34. Kudrow L. The cyclic relationship of natural illumination to cluster period frequency. Cephalalgia. 1987;7(Suppl 6):76-8. 
35. Hagedorn A, Snoer A, Jensen R, Haddock B, Barloese $\mathrm{M}$. The spectrum of cluster headache: a case report of 4600 attacks. Cephalalgia Int J Headache. 2019;39(9):1134-42.

36. Khalsa SB, Jewett ME, Cajochen C, Czeisler CA. A phase response curve to single bright light pulses in human subjects. J Physiol. 2003;549(Pt 3):945-52.

37. Buijs RM, Escobar C, Swaab DF. The circadian system and the balance of the autonomic nervous system. Handb Clin Neurol. 2013;117:173-91.

38. Pfeffer M, Korf HW, Wicht H. Synchronizing effects of melatonin on diurnal and circadian rhythms. Gen Comp Endocrinol. 2018;258:215-21.

39. Dijk D, Lockley S. Integration of human sleep-wake regulation and circadian rhythmicity. Appl Physiol. 2002;92:852-62.

40. Ofte HK, Tronvik E, Alstadhaug KB. Lack of association between cluster headache and PER3 clock gene polymorphism. J Headache Pain. 2015;17:18.

41. Lund NLT, Snoer AH, Jennum PJ, Jensen RH, Barloese MCJ. Sleep in cluster headache revisited: results from a controlled actigraphic study. Cephalalgia. 2019;39:742-9.

42. Lund N, Petersen A, Snoer A, Jensen RH, Barloese M. Cluster headache is associated with unhealthy lifestyle and lifestyle-related comorbid diseases: results from the Danish Cluster Headache Survey. Cephalalgia. 2019;39:254-63.

43. Brennan KC, Charles A. Sleep and headache. Semin Neurol. 2009;29(4):406-18.

44. Fuller PM, Gooley JJ, Saper CB. Neurobiology of the sleep-wake cycle: sleep architecture, circadian regulation, and regulatory feedback. J Biol Rhythms. 2006;21(6):482-93.

45. May A, Bahra A, Buchel C, Frackowiak R, Goadsby P. Hypothalamic activation in cluster headache attacks. Lancet. 1998;352:275-8.

46. May A, Goadsby PJ. Cluster headache: imaging and other developments. Curr Opin Neurol. 1998;11(3): 199-203.

47. Aurora SK. Etiology and pathogenesis of cluster headache. Curr Pain Headache Rep. 2002;6(1):71-5.

48. Schulte LH, Haji AA, May A. Phase dependent hypothalamic activation following trigeminal input in cluster headache. J Headache Pain. 2020;21(1):30.

49. Guo S, Vollesen AL, Hansen RD, et al. Part I: Pituitary adenylate cyclase-activating polypeptide-38 induced migraine-like attacks in patients with and without familial aggregation of migraine. Cephalalgia. 2017;37(2):125-35.

50. Guo S, Vollesen AL, Hansen YB, et al. Part II: Biochemical changes after pituitary adenylate cyclaseactivating polypeptide-38 infusion in migraine patients. Cephalalgia. 2017;37(2):136-47.

51. Denuelle M, Fabre N, Payoux P, Chollet F, Geraud G. Hypothalamic activation in spontaneous migraine attacks. Headache. 2007;47(10):1418-26.

52. Maniyar FH, Sprenger T, Monteith T, Schankin C, Goadsby PJ. Brain activations in the premonitory phase of nitroglycerin-triggered migraine attacks. Brain. 2014;137(Pt 1):232-41.

53. Schulte LH, May A. The migraine generator revisited: continuous scanning of the migraine cycle over 30 days and three spontaneous attacks. Brain. 2016;139(Pt 7):1987-93.

54. Goadsby PJ, May A. PET demonstration of hypothalamic activation in cluster headache. Neurology. 1999;52(7):1522.

55. Vaudry D, Falluel-Morel A, Bourgault S, et al. Pituitary adenylate cyclase-activating polypeptide and its receptors: 20 years after the discovery. Pharmacol Rev. 2009;61(3):283-357.

56. Dickson L, Finlayson K. VPAC and PAC receptors: From ligands to function. Pharmacol Ther. 2009;121(3):294-316.

57. Akerman S, Goadsby PJ. Neuronal PAC1 receptors mediate delayed activation and sensitization of trigeminocervical neurons: relevance to migraine. Sci Transl Med. 2015;7(308):308ra157.

58. Tuka B, Helyes Z, Markovics A, et al. Alterations in PACAP-38-like immunoreactivity in the plasma during ictal and interictal periods of migraine patients. Cephalalgia. 2013;33(13):1085-95.

59. Schytz HW, Birk S, Wienecke T, Kruuse C, Olesen J, Ashina M. PACAP38 induces migraine-like attacks in patients with migraine without aura. Brain. 2009;132(Pt 1):16-25.

60. Banks WA, Uchida D, Arimura A, Somogyvari-Vigh A, Shioda S. Transport of pituitary adenylate cyclase-activating polypeptide across the bloodbrain barrier and the prevention of ischemia-induced death of hippocampal neurons. Ann N Y Acad Sci. 1996;805:270-7.

61. Mizushima H, Banks WA, Dohi K, Shioda S, Matsumoto H, Matsumoto K. The effect of cardiac arrest on the permeability of the mouse blood-brain and blood-spinal cord barrier to pituitary adenylate 
cyclase activating polypeptide (PACAP). Peptides. 1999;20(11):1337-400.

62. Fukuhara C, Inouye SI, Matsumoto Y, Tsujimoto G, Aoki K, Masuo Y. Pituitary adenylate cyclase-activating polypeptide rhythm in the rat pineal gland. Neurosci Lett. 1998;241(2-3):115-8.

63. Fang J, Payne L, Krueger JM. Pituitary adenylate cyclase activating polypeptide enhances rapid eye movement sleep in rats. Brain Res. 1995;686(1): 23-8.

64. Murck H, Steiger A, Frieboes RM, Antonijevic IA. Pituitary adenylate cyclase-activating peptide affects homeostatic sleep regulation in healthy young men. Am J Physiol Endocrinol Metab. 2007;292(3):E853-857.

65. Ahnaou A, Basille M, Gonzalez B, et al. Long-term enhancement of REM sleep by the pituitary adenylyl cyclase-activating polypeptide (PACAP) in the pontine reticular formation of the rat. Eur $\mathrm{J}$ Neurosci. 1999;11(11):4051-8.

66. Stillman M, Spears R. Endocrinology of cluster headache: potential for therapeutic manipulation. Curr Pain Headache Rep. 2008;12(2):138-44.

67. Grover P, Pereira E, Green A, et al. Deep brain stimulation for cluster headache. J Clin Neurosci. 2009;16:861-6.

68. Chiou LC, Lee HJ, Ho YC, et al. Orexins/hypocretins: pain regulation and cellular actions. Curr Pharm Des. 2010;16(28):3089-100.

69. Sakurai T, Amemiya A, Ishii M, et al. Orexins and orexin receptors: a family of hypothalamic neuropeptides and $G$ protein-coupled receptors that regulate feeding behavior. Cell. 1998;92(4):573-85.

70. Mignot E, Lammers GJ, Ripley B, et al. The role of cerebrospinal fluid hypocretin measurement in the diagnosis of narcolepsy and other hypersomnias. Arch Neurol. 2002;59(10):1553-622.

71. Leone M, Lucini V, D'Amico D. Twenty-four-hour melatonin and cortisol plasma levels in relation to timing of cluster headache. Cephalalgia. 1995;15: 224-9.

72. Dodick DW, Eross EJ, Parish JM, Silber M. Clinical, anatomical, and physiologic relationship between sleep and headache. Headache. 2003;43(3):282-92.

73. Halasz P, Terzano M, Parrino L, Bodizs R. The nature of arousal in sleep. J Sleep Res. 2004;13(1):1-23.

74. Bruni O, Russo PM, Violani C, Guidetti V. Sleep and migraine: an actigraphic study. Cephalalgia. 2004;24(2):134-9.
75. Della Marca G, Vollono C, Rubino M, Capuano A, Di Trapani G, Mariotti P. A sleep study in cluster headache. Cephalalgia. 2006;26(3):290-4.

76. Marshansky S, Mayer P, Rizzo D, Baltzan M, Denis R, Lavigne GJ. Sleep, chronic pain, and opioid risk for apnea. Progress Neuropsychopharmacol Biol Psychiatry. 2018;87(Part B):234-44.

77. Russell MB, Kristiansen HA, Kværner KJ. Headache in sleep apnea syndrome: epidemiology and pathophysiology. Cephalalgia. 2014;34(10):752-5.

78. Ulfberg J, Carter N, Talback M, Edling C. Headache, snoring and sleep apnoea. J Neurol. 1996;243(9): $621-5$.

79. Alberti A, Mazzotta G, Gallinella E, Sarchielli P. Headache characteristics in obstructive sleep apnea syndrome and insomnia. Acta Neurol Scand. 2005;111(5):309-16.

80. Jensen R, Olsborg C, Salvesen R, Torbergsen T, Bekkelund SI. Is obstructive sleep apnea syndrome associated with headache? Acta Neurol Scand. 2004;109(3):180-4.

81. Snoer A, Lund N, Beske R, Jensen R, Barloese M. Preattack signs and symptoms in cluster headache: characteristics and time profile. Cephalalgia Int J Headache. 2018;38(6):1128-37.

82. Schürks M, Diener H-C. Cluster headache and lifestyle habits. Curr Pain Headache Rep. 2008;12(2): 115-21.

83. Lund NLT, Snoer AH, Jensen RH. The influence of lifestyle and gender on cluster headache. Curr Opin Neurol. 2019;32(3):443-8.

84. Sjöstrand C, Russell MB, Ekbom K, Waldenlind E. Familial cluster headache: demographic patterns in affected and nonaffected. Headache J Head Face Pain. 2010;50(3):374-82.

85. Vollesen AL, Benemei S, Cortese F, et al. Migraine and cluster headache-the common link. J Headache Pain. 2018;19(1):89.

86. de Tommaso M, Delussi M. Circadian rhythms of migraine attacks in episodic and chronic patients: a cross sectional study in a headache center population. BMC Neurol. 2018;18:94-103.

87. Hoffmann J, May A. Diagnosis, pathophysiology, and management of cluster headache. Lancet Neurol. 2018;17(1):75-83.

88. Schürks M, Kurth T, De Jesus J, Jonjic M, Rosskopf D, Diener HC. Cluster headache: clinical presentation, lifestyle features, and medical treatment. Headache J Head Face Pain. 2006;46(8):1246-54. 
89. Rozen T, Fischman R. Female cluster headache in the United States of America? What are the gender differences? Results from the United States Cluster Headache Survey. J Neurol Sci. 2012;317:17-28.

90. Taga A, Manzoni GC, Russo M, Paglia MV, Torelli P. Childhood-onset cluster headache: observations from a personal case-series and review of the literature. Headache. 2018;58(3):443-54.
91. Lund N, Barloese M, Petersen A, Haddock B, Jensen R. Chronobiology differs between men and women with cluster headache, clinical phenotype does not. Neurology. 2016;88(11):1069-76.

92. Palacios-Cena D, Talavera B, Lopez-Ruiz P, et al. Living with cluster headache: a qualitative study of patients' perspectives. Headache. 2016;56(7): 1171-82. 